\title{
A COR DO SUCESSO: EFEITOS DA PERFORMANCE SOCIAL E ECONÔMICA NO BRANQUEAMENTO E NA INFRA-HUMANIZAÇÃO DOS NEGROS NO BRASIL
}

\author{
Marcus Eugênio O. Lima ${ }^{1}$ \\ Universidade Federal da Bahia \\ Jorge Vala $^{2}$ \\ Instituto de Ciências Sociais - Universidade de Lisboa
}

\begin{abstract}
Este estudo examina os efeitos da cor da pele e da performance social dos grupos no branqueamento e na infra-humanização. Os dados deste estudo foram coletados em três capitais do Brasil, em três regiões diferentes. As principais hipóteses são: a) os Negros serão mais infrahumanizados do que os Brancos; b) os grupos que fracassam socialmente serão mais infra-humanizados do que os grupos que obtêm sucesso; e c) os grupos com sucesso deverão ser percebidos como mais brancos do que os que fracassam. Os resultados, obtidos junto a 175 estudantes universitários brancos, de três universidades privadas, indicam que as hipóteses são parcialmente confirmadas. Os grupos que fracassam são infra-humanizados quando comparados aos que obtêm sucesso e os grupos que obtêm sucesso são branqueados e os que fracassam enegrecidos, ao nível da percepção subjetiva da cor da pele. No entanto, a infra-humanização dos negros acontece com a mediação do branqueamento. Esses resultados são discutidos à luz das novas teorias psicossociais sobre o racismo.
\end{abstract}

Descritores: Grupos sociais. Racismo. Fatores socioculturais.

1 Endereço para correspondência: Marcus E. O. Lima, Cond. San Diego, casa 10, Loteamento Aquários, Aruana, Aracaju, Sergipe, CEP 49035-000. Endereço eletrônico: meolima@uol.com.br

2 Endereço eletrônico: jorge.vala@ics.ul.pt 
oa parte da mais recente literatura da Psicologia Social sobre o racismo 3 afirma que o racismo ou a racialização ${ }^{3}$ das diferenças parte da crença de que as diferenças superficiais, reais ou imaginárias entre os grupos possuem um fundamento biológico, fixo e imutável (Lima, 2003). Nessa direção, Vala e Lima (2002) argumentam que o racismo se fundamenta na crença de que existe uma relação de causalidade entre variações estruturais aparentes (e.g., a cor da pele, o formato do nariz etc.) e variações processuais ou de conteúdo internas (e.g., as capacidades intelectuais, a personalidade, caráter etc.). É nesse sentido que qualquer racismo é sempre uma forma de essencialização das diferenças entre os grupos (Leyens et al., 2000).

Embora saibamos que as categorias sociais não possuem essências que as diferenciem de outras categorias sociais, não se pode negar a tendência que a epistemologia do senso comum e mesmo a científica têm em atribuir essências diferentes aos diferentes grupos sociais. Essa tendência incide, sobretudo, nas representações sociais construídas sobre os grupos minoritários (Vala, Brito, \& Lopes, 1999). Além desta tendência, existem duas outras, a tendência ao etnocentrismo (Campbell \& McCandless, 1951) e a tendência de favorecimento do endogrupo ou grupo de pertença (Tajfel, 1978), que, quando associadas, podem fazer com que a atribuição de essências diferentes aos diversos grupos engendre uma atribuição de essências superiores ao grupo de pertença e de essências inferiores ao exogrupo (grupo do outro).

Seguindo essa linha de argumentação, podemos pensar que o racismo parte de uma lógica essencialista, para construir hierarquias que infrahumanizam os grupos minoritários ou de baixo status. Pois estes (os grupos minoritários) devem possuir as "más essências", ao passo que os maioritários ou de alto status devem possuir as "boas essências". Neste trabalho, pro-

3 Embora cientificamente não haja mais fundamentos para se falar em "grupos raciais", em termos sociais e representacionais alguns grupos minoritários fenotipicamente definidos como "diferentes", continuam sendo percebidos e avaliados em termos biológicos ou racializantes (Vala, Lopes, \& Brito, 1999). É neste sentido que utilizaremos ao longo deste trabalho expressões tais como “racialização" e "grupos racializados”. 
curamos analisar o modo pelo qual grupos de pessoas brancas e negras de alto e de baixo status social são representados em termos da atribuição de essências tipicamente humanas. De outra maneira, analisamos os efeitos da cor da pele e do status dos grupos na sua infra-humanização e no branqueamento.

\section{A “essência humana” e os mecanismos de infra-humanização}

A essencialização quando aplicada aos exogrupos ou aos grupos minoritários implica sempre a negação, em maior ou menor grau, de determinadas características que compõem a "essência humana”, ou seja, implica em "infra-humanização”. Mas que características definem a "essência humana”?

Vários estudos têm verificado que as características tipicamente humanas são os valores (Schwartz \& Struch, 1989), a cultura (Moscovici \& Pérez, 1999), a linguagem, a inteligência e a capacidade de expressar sentimentos (Leyens et al., 2000). De modo que, negar aos exogrupos algum desses elementos é uma forma de infra-humanização.

Bar-Tal (1989), analisando o modo como os Judeus foram infrahumanizados pelo regime nazista, afirma que a infra-humanização envolve a categorização de um grupo como não humano. Isso ocorre através do uso de rótulos ou categorias de criaturas consideradas subumanas, tais como "raças inferiores” e "animais”, ou pelo uso de categorizações supra-humanas negativamente percebidas, tais como "demônios" e "monstros". A infrahumanização é feita mediante a atribuição de traços ou características que são socialmente muito desvalorizadas na sociedade na qual ocorre.

\section{Evidências empíricas da infra-humanização do outro}

Uma análise da trajetória empírica da infra-humanização na Psicologia Social pode seguir três eixos: a infra-humanização no plano dos 
valores, a infra-humanização no plano dos traços culturais e naturais e a infra-humanização no plano das emoções. De uma maneira mais específica, os principais indicadores de infra-humanização utilizados nos estudos são: a) a negação da capacidade do exogrupo de adotar valores tipicamente humanos e a diferenciação intergrupal ao nível dos valores; b) a desculturalização dos grupos racializados, através de uma atribuição diferenciada de características naturais e culturais; e c) a sub-atribuição de sentimentos ao exogrupo. Neste trabalho, iremos nos deter apenas nos dois últimos indicadores de infra-humanização

\section{A infra-humanização do outro no plano dos afetos}

Leyens et al. (2000), numa análise da face emocional do racismo, afirmam que a atribuição diferenciada de emoções primárias e emoções secundárias (sentimentos) a membros do endogrupo e do exogrupo pode ser um indicador de infra-humanização ou de racismo. As emoções primárias são definidas pelos autores como características que são compartilhadas por seres humanos e também por animais, uma vez que são fisiologicamente determinadas, são rápidas ou pouco duradouras na sua expressão, refletemse externamente e, normalmente, podem ser expressas desde muito cedo na vida. Exemplos de emoções primárias são a raiva, o medo, a surpresa, o prazer etc. As emoções secundárias ou sentimentos, por sua vez, são unicamente humanas e têm longa duração, são menos intensas, envolvem reflexões morais, cognições e sensibilidade, são menos visíveis, aparecem mais tarde na vida e são mais internamente causadas do que as emoções primárias. Exemplos de sentimentos são o amor, a resignação, a esperança, o arrependimento etc.

Leyens et al. (2001) realizam um conjunto de estudos para verificar se existem diferenças na atribuição de emoções primárias e sentimentos aos grupos sociais e se essa diferenciação é influenciada pelo status social dos grupos envolvidos. No primeiro estudo, universitários das Ilhas Canárias (grupo de baixo status), de Madrid e de Barcelona (grupos de alto status) 
recebiam uma lista com 8 características neutras e 8 emoções, sendo 4 emoções primárias (e.g., coragem, assombro, exaltação e surpresa) e 4 emoções secundárias ou sentimentos (e.g., nostalgia, compaixão, orgulho e arrependimento). Os participantes deveriam escolher dentre as 16 palavras aquelas que consideravam típicas dos membros do exogrupo. Os resultados indicaram que ambos os grupos (baixo e alto status) escolhiam mais emoções secundárias para o seu grupo do que para o outro grupo, não havendo diferenças no plano das emoções primárias. Em dois outros estudos, Leyens et al. replicam esses achados e concluem que a melhor leitura dos resultados encontrados é a de que são atribuídas menos emoções secundárias ou sentimentos aos membros do exogrupo do que aos membros do endogrupo, não havendo diferenças no plano das emoções primárias.

Com base nesses pressupostos, hipotetizamos que: a) sejam atribuídos mais sentimentos a grupos que obtêm sucesso (alto status) do que a grupos que fracassam (baixo status) (H1); b) sejam atribuídos mais sentimentos aos Brancos do que aos Negros (H2); e c) sejam atribuídas mais emoções positivas aos grupos com sucesso do que aos que fracassam (H3).

\section{A infra-humanização do outro no plano da desculturalização}

Moscovici e Pérez (1999) argumentam que as representações sociais construídas sobre os grupos racializados podem estruturar-se em dois eixos: o eixo dos traços de natureza e o eixo dos traços de cultura. Os traços "naturais” são definidos como características que são usadas de maneira indiferenciada nas descrições de seres humanos e nas descrições de animais. Já os traços “culturais” são aqueles que são típicos dos seres humanos (Moscovici \& Pérez, 1997). Para testar essa hipótese, Moscovici e Pérez realizam um estudo sobre as representações sociais construídas acerca dos ciganos na Espanha. Os participantes do estudo, espanhóis não ciganos, liam um texto sobre as estratégias utilizadas ao longo da história para assimilar os ciganos à sociedade dominante. Metade dos participantes foi informada de que os ciganos aceitaram essas estratégias e deixaram-se integrar culturalmente, a 
outra metade foi informada de que os ciganos não aceitaram a integração cultural. Em seguida, os participantes deveriam descrever os ciganos com base numa lista de adjetivos "naturais positivos" (e.g., intuitivo, livre, fisicamente hábil, espontâneo e com ritmo musical), "naturais negativos” (e.g., selvagem, impulsivo, agressivo, visceral e ruidoso), "culturais positivos" (e.g., criativo, leal à sua identidade, solidário, mentalmente habilidoso e extrovertido) e “culturais negativos" (e.g., vingativo, perverso, manipulador, falso ou mentiroso e mal-intencionado). Moscovici e Pérez (1999) verificam que os ciganos que recusaram a integração cultural foram mais descritos em termos de traços naturais do que os ciganos que se deixaram integrar. Esses resultados são replicados num segundo estudo, realizado também na Espanha, dois anos mais tarde (Moscovici \& Pérez, 1999).

Num contexto mais amplo de relações racializadas, Correia, Brito, Vala e Pérez (2001) realizaram um estudo comparativo do modo como os ciganos são representados em termos de traços naturais e culturais, em vários países da Europa. Correia et al. (2001), utilizando os mesmos traços naturais e culturais do estudo original de Moscovici e Pérez (1999), verificaram que os ciganos são infra-humanizados na Europa, através de uma maior atribuição de traços naturais do que de traços culturais.

De acordo com esses pressupostos, podemos hipotetizar que: a) sejam atribuídas mais características culturais para os grupos com sucesso social (alto status) do que para os grupos que fracassam socialmente (H4); e b) sejam atribuídas mais características culturais para os Brancos do que para os Negros (H5).

\section{Branqueamento e infra-humanização dos Negros no Brasil}

O racismo, na atualidade, possui muitas formas de expressão (ver Gaertner \& Dovidio, 1986; Katz \& Hass, 1988; Kinder \& Sears, 1981; McConahay \& Hough, 1976; Pettigrew \& Meertens, 1995; Turra \& Venturi, 1995). Cada uma dessas várias formas de expressão do racismo reflete o contexto histórico, econômico e cultural no qual emerge (Camino, Silva, 
Machado, \& Pereira, 2001; França \& Monteiro, 2002; Vala, Brito, \& Lopes, 1999). Sendo assim, podemos esperar que, no Brasil, dada a composição etnográfica peculiar da nossa população, a infra-humanização dos negros seja permeada pelo branqueamento. $\mathrm{O}$ branqueamento é aqui entendido como um conjunto de normas, valores e atitudes associados aos "brancos", que as pessoas não brancas adotam ou incorporam, a fim de assemelhar-se ao modelo "branco" dominante e, assim, construir uma identidade racial positiva (Piza, 2000). Cabe referir ainda que os brancos podem utilizar o branqueamento como forma de categorização e discriminação social. Nesse sentido, trata-se de uma associação da cor da pele ao status socioeconômico dos grupos.

É nessa direção que vários estudiosos do racismo no Brasil têm afirmado que existe uma forte relação entre o fracasso social e econômico com a cor negra e entre o sucesso e a cor branca (Adorno, 1996; Degler, 1971; Guimarães, 1999). De tal maneira que o branqueamento parece ser o elemento principal que diferencia o racismo brasileiro de outros racismos (Skidmore, 1989).

Como argumentam Roger Bastide e Florestan Fernandes (1959), existe no Brasil uma forte correlação entre a classe social e a cor da pele, quanto mais “caucasóide” o fenótipo, maior o status, quanto mais “negróide” menor status social. De modo que o preconceito no Brasil seria um preconceito misto, de classe e de raça. Não seria só de raça, porque há "brancos" que aceitam os "negros", nem só de classe, porque certas restrições atingem a todos os "negros", mesmo os mais ricos (Fernandes, 1965). É por causa desse fato que o racismo brasileiro esteve sempre circunstanciado por questões de classe social. Tanto que alguns estudiosos do fenômeno chamam a essa associação de “raça social” (Wagley citado por Degler, 1971; ver Lima, 2003, para uma revisão).

De fato, o racismo no Brasil manifesta-se pelo branqueamento dos indivíduos que fazem sucesso e o enegrecimento ou empardecimento dos que fracassam. Sérgio Adorno (1996), analisando Boletins de Ocorrências (BOs) de crimes violentos em São Paulo, no ano de 1990, demonstra que, a depender do curso do processo, o réu pode mudar de cor. Se for progressivamente 
inocentado pelas evidências, pode se tornar branco ou moreno claro nas descrições feitas nos BOs. Por outro lado, se as evidências apontarem para a sua culpabilidade, pode se tornar moreno escuro ou mesmo negro.

É nesse sentido que Harris (1970), estudando a relação entre cor e performance social no interior da Bahia, considera que a associação entre cor e sucesso social no Brasil é tão forte que se pode formular o seguinte cenário:

Um negro é qualquer um dos seguintes:

Um branco muito pobre

Um mulato muito pobre

Um mulato pobre

Um negro muito pobre

Um negro pobre

Um negro medianamente rico

Um branco é qualquer um dos seguintes:

Um branco muito rico

Um branco medianamente rico

Um branco pobre

Um mulato muito rico

Um mulato medianamente rico

Um negro muito rico

Com base nesses dados, hipotetizamos que os grupos com sucesso social sejam percebidos como mais brancos do que os grupos que fracassam socialmente, que devem ser enegrecidos (H6).

Todavia, as várias regiões do Brasil, graças à sua composição etnográfica e formação sócio-histórica próprias, apresentam diferenciadas matrizes 
de racismo e discriminação do negro (Alencastro, 1998; Carneiro, 1998; Fernandes, 1989; Schwarcz \& Queiroz, 1996; Turra \& Venturi, 1995). Assim, torna-se necessário estender o foco das análises sobre a infrahumanização dos Negros para outras regiões do Brasil. De modo que resolvemos aplicar o mesmo instrumento, em três das regiões do país: a Região Centro-Oeste, a Região Sudeste e a Região Nordeste. Fato que pode permitir encontrar uma configuração diferenciada da infra-humanização dos Negros em cada Região, embora não tenhamos hipóteses formuladas para essa possível diferenciação.

\section{Método}

Foram entrevistados 175 estudantes brancos de universidades particulares, em três regiões do Brasil. Na Região Nordeste (Aracaju), foram 60 estudantes de cursos na área de Ciências Humanas da Universidade Tiradentes; na Região Centro-Oeste (Goiânia), foram 60 estudantes de Psicologia da Universidade Católica de Goiás; e, na Região Sudeste (São Paulo), 55 estudantes de vários cursos da PUC de São Paulo.

Os estudantes foram abordados em sala de aula e convidados a participar de um estudo na área de Psicologia Social sobre a formação de impressões.

Foi utilizado um delineamento fatorial 2 (Performance socioeconômica: Sucesso vs. Fracasso) X 2 (cor da pele: Brancos vs. Negros) X 3 (Contexto da resposta: Regiões Sudeste/Nordeste/Centro-Oeste). Os participantes foram distribuídos aleatoriamente por cada uma das condições, em grupos de 15 sujeitos cada (Aracaju e Goiânia) e em grupos de 14, 14, 14 e 13 (São Paulo).

O material utilizado foi um questionário no qual constava uma história sobre a situação de um grupo de brasileiros que obtêm sucesso econômico e social ou que fracassa. Isso permitiu a divisão dos participantes em quatro grupos. Cada participante lia apenas uma das histórias. A cor da pele dos grupos-alvo foi manipulada através da colocação de uma fotografia anexada à história. Foram utilizadas 4 fotografias, sendo uma foto para cada condição de 
resposta. A principal alteração nas fotos foi a colocação de roupas mais sofisticadas na condição de sucesso e mais simples na condição de fracasso. As fotos foram pré-analisadas quanto à atratividade física, qualidade gráfica, cor da pele dos alvos e idade, e não apresentaram impedimentos à sua utilização.

\section{Questões analisadas}

a) Sentimentos e Emoções atribuídos aos grupos-alvo - utilizamos um questionário composto por 12 itens, considerados em termos de conteúdo e valência (ver Leyens et al., 2000). Assim, foram utilizadas 3 emoções secundárias positivas (amor, esperança e felicidade, Alfa $=0.75$ ), 3 emoções secundárias negativas (arrependimento, angústia e vergonha, Alfa =0.59), 3 emoções primárias positivas (alegria, prazer e vigor, Alfa $=0.81$ ) e 3 emoções primárias negativas (nojo, raiva e medo, Alfa $=0.58$ ). Os Alfas obtidos indicam bons ou regulares índices de confiabilidade interna das escalas. Os participantes deveriam indicar, através de uma escala que varia de 0 (nunca sentem isso) a 5 (sentem isso o tempo todo), a freqüência com que os membros do grupos-alvo sentem cada uma dessas emoções.

b) Traços de Natureza e de Cultura atribuídos aos grupos - foram analisados em termos de valência e conteúdo. Foram utilizados 12 traços. O conteúdo dos traços foi indicado através de 2 dimensões teóricas de representação dos grupos sociais: traços de natureza e traços de cultura. Os traços poderiam ainda ser positivos ou negativos. Assim, foram compostas 4 dimensões de representação dos grupos, todas com bons ou regulares índices de consistência interna: cultura positiva (inteligentes, sábios e solidários, Alfa = 0.67), cultura negativa (ignorantes, infantis e falsos, Alfa $=0.73$ ), natureza positiva (alegres, espertos e espontâneos, Alfa $=0.61$ ) e natureza negativa (agressivos, descontrolados e impulsivos, Alfa $=0.85$ ). A escala para medir a atribuição variava de 0 (nada característico) a 4 (totalmente característico).

c) O Branqueamento dos grupos-alvo - medido por intermédio de uma escala bipolar, tipo diferenciador semântico, colocada no final do questionário, e com 7 intervalos; sendo 1 (brancos), 4 (mulatos) e 7 (negros). 
Cor da pele, sucesso social e infra-humanização

\section{Resultados e Discussão}

Todas as análises foram feitas considerando a Região como variável antecedente, juntamente com a cor da pele e a performance dos grupos-alvo. Para efeitos de síntese, neste texto, não apresentaremos todos os resultados encontrados e, pela natureza desta publicação, omitiremos os quadros e referiremos os resultados, apenas textualmente. Importante referir, ainda, que tomaremos a Universidade e sua posição geográfica como indicador da Região. Assim, muitas vezes, falaremos de Região Sudeste, mas os nossos dados referem-se a apenas 55 estudantes da PUC de São Paulo. De igual forma, falaremos de Região Centro-Oeste e estaremos considerando apenas 60 estudantes da Universidade Católica de Goiânia e, no Nordeste, serão apenas outros 60 estudantes de uma universidade particular de Aracaju. Evidentemente, não objetivamos generalizações com tão pequena e estratificada amostra, apenas utilizamos o termo "Região" enquanto categoria descritiva, que, no entanto, pode indicar diferenças nas expressões do racismo.

\section{A infra-humanização em termos de emoções secundárias e primárias}

Para verificarmos o efeito da cor da pele dos grupos, da Região e da performance dos grupos na atribuição de emoções primárias (emoções) e secundárias (sentimentos), realizamos uma Análise de Variância Multivariada (MANOVA), com medidas repetidas, tomando como variáveis independentes interparticipantes: a cor da pele dos grupos, a performance socioeconômica e a Região dos respondentes. As variáveis independentes intraparticipantes foram as emoções e os sentimentos, positivos e negativos, atribuídos aos grupos. A variável dependente foi a média de atribuição. Os resultados indicam um efeito principal do conteúdo dos traços4: são atribuídas mais emoções primárias $(M=2.38)$ do que sentimentos $(M=2.12)$. Esse efeito é qualificado por uma interação entre conteúdo e performance ${ }^{5}$. Como

$4 \quad F(1,160)=31.21, p<.001$

$5 \quad F(1,160)=18.36, p<.001$ 
esperado (H1), ocorre uma maior atribuição de sentimentos aos grupos que obtêm sucesso $(M=2.27)$ do que aos grupos que fracassam $(M=1.97)$; não havendo diferenças na atribuição de emoções primárias aos que fracassam $(M=2.43)$ e aos que obtêm sucesso $(M=2.33)$. De tal modo que, assim como verificaram Leyens et al. (2001), a infra-humanização dos grupos que fracassam em relação aos que obtêm sucesso ocorre apenas no plano dos sentimentos ou emoções secundárias, uma vez que não há diferenças na atribuição de emoções primárias a esses dois grupos.

Diferentemente do esperado na nossa segunda hipótese (H2), que previa uma maior atribuição de sentimentos aos Brancos do que aos Negros, os resultados indicam que a interação entre cor da pele e conteúdo dos afetos não foi encontrada6.

Entretanto, verificamos uma interação quádrupla, envolvendo a Região de resposta, a cor da pele e a performance dos grupos-alvo e o conteúdo dos afetos7. São atribuídos mais sentimentos para os negros que fracassam na Região Sudeste $(M=2.54)$ do que na Nordeste $(M=1.74)$ e Centro-Oeste $(M=$ 1.67). Nessa última Região, são atribuídos menos sentimentos aos brancos que fracassam $(M=1.59)$ do que aos brancos que obtêm sucesso $(M=2.36)$.

Em termos da valência das emoções, verificamos um efeito de interação entre a Região e a valência dos afetos8. São atribuídas menos emoções negativas aos grupos na Região Centro-Oeste $(M=1.94)$ do que na Sudeste $(M=2.41)$ e na Nordeste $(M=2.30)(S N K, p<.05)$. Não houve diferenças na atribuição das emoções positivas aos grupos nas 3 regiões ( $M s=2.32$; 2.35; 2.31).

A nossa terceira hipótese previa uma maior atribuição de emoções positivas aos grupos com sucesso do que aos grupos que fracassam. Essa hipótese foi verificada por meio da interação entre performance e valência dos afetos ${ }^{9}$. Como previsto, na nossa terceira hipótese (H3), são atribuídos mais

$6 \quad F(1,160)<1, n s$.

$7 \quad F(2,160)=7.03, p=.001$

$8 \quad F(2,160)=4.29, p<.05$

$9 \quad F(1,160)=115.63, p<.0001$ 
afetos positivos para os grupos com sucesso $(M=2.76)$ do que para os que fracassam $(M=1.80)$ e mais afetos negativos para os que fracassam $(M=$ 2.60) do que para os que obtêm sucesso $(M=1.84)$.

\section{A infra-humanização dos grupos no plano da desculturalização}

Em seguida, analisamos a infra-humanização dos grupos através da atribuição de traços de cultura e de natureza. Novamente, realizamos uma MANOVA com medidas repetidas, tomando a cor da pele e a performance dos grupos-alvo e a Região dos respondentes como variáveis independentes interparticipantes, sendo que as variáveis independentes intraparticipantes foram o conteúdo dos traços (Cultura vs. Natureza) e a valência (Positivos vs. Negativos). A variável dependente foi a média na atribuição de cada conjunto de características aos grupos.

Primeiramente, verificamos um efeito principal do conteúdo dos traços10. Este efeito indica que são atribuídos mais traços de natureza ( $M=$ 2.04) do que de cultura $(M=1.67)$ na caracterização dos grupos. Este resultado é, no entanto, qualificado pela interação entre conteúdo e performance11. Na nossa quarta hipótese (H4), predizíamos que seriam atribuídas mais características culturais aos grupos com sucesso do que para os grupos que fracassam socialmente. Os resultados encontrados confirmam parcialmente essa expectativa, uma vez que são atribuídas mais características "naturais" $(M=2.40)$ do que "culturais" aos grupos que fracassam $(M=1.80)$ e mais traços "naturais" para os que fracassam do que para os que obtêm sucesso $(M=1.69)$; sem ter havido diferenças em termos de traços "naturais” e "culturais” para os grupos com sucesso. De modo que, ao nível das características naturais confirma-se a infra-humanização dos que fracassam, os quais são mais representados através dessas características do que os que obtêm sucesso.

$10 F(1,162)=87.65, p<.0001$

$11 F(1,162)=33.02, p<.001$ 
A nossa quinta hipótese previa uma maior atribuição das características culturais para os Brancos do que para os Negros (H5). Esta hipótese não se confirmou, uma vez que a interação entre cor da pele e conteúdo das características não foi significativa ${ }^{12}$.

\section{Efeitos da performance socioeconômica, da cor da pele e do branqueamento na infra-humanização dos grupos}

A fim de testar a hipótese do branqueamento, que afirmava que os grupos com sucesso seriam percebidos como mais brancos e os que fracassam como mais negros (H6), realizamos uma Análise de Variância (Univaridada), tomando como variável dependente da cor da pele dos grupos, da Região e da performance, a cor atribuída. Os resultados indicam um efeito principal da cor da pele objetiva dos grupos ${ }^{13}$. Os brancos são percebidos como mais brancos $(M=4.45)$ do que os negros $(M=3.04)$. Na direção da nossa hipótese verificamos um efeito principal da performance ${ }^{14}$. Como hipotetizado, os grupos que obtêm sucesso são percebidos como mais bran$\cos (M=4.09)$ do que os grupos que fracassam, que são enegrecidos ( $M=$ 3.42). Este resultado confirma os dados de outros estudos empíricos, tais como o de Adorno (1996) e teóricos, tais como o estudo de Harris (1970) e o de Degler (1971), sobre o branqueamento do sucesso social no Brasil.

\section{O campo semântico da infra-humanização dos negros}

A fim de tornarmos mais clara a apresentação dos resultados e de obtermos uma síntese dos indicadores de infra-humanização, juntamente com o indicador de branqueamento, realizamos uma Análise de Correspondências Múltiplas, seguindo um procedimento que torna essa técnica análoga ao
$12 \quad F(1,162)=1.20, n s$
$13 F(1,163)=28.64, p<.001$
$14 F(1,163)=6.46, p=.01$ 
SPAD-T (Carvalho, 1990). A Análise de Correspondência Múltipla do tipo Homals é uma técnica que permite representar a relação entre três ou mais variáveis nominais, em poucas dimensões, normalmente duas ou três. A Homals é análoga à Análise dos Componentes Principais, sendo apropriada para dados nominais (Pestana \& Gageiro, 1998).

Para realizarmos essa análise, primeiramente, recodificamos a escala de atribuição dos sentimentos e emoções e dos traços de natureza e cultura. Transformamos essas escalas em variáveis dicotômicas, utilizando a mediana como valor-critério. De modo que os valores iguais ou acima da mediana foram considerados como indicadores da atribuição da característica em foco (i.e., natureza, cultura, sentimentos ou emoções). Também a percepção subjetiva da cor da pele (branqueamento) foi recodificada e transformada numa variável nominal com três categorias (Brancos, Mulatos e Negros). A Região foi tomada como uma variável suplementar ou estruturante do campo representacional, de acordo com os procedimentos sugeridos por Carvalho (1990).

Os resultados indicam que, como já observado, a Região de resposta não produz grandes diferenças na infra-humanização e no branqueamento dos grupos. As três regiões aparecem muito próximas no espaço semântico representado na Figura 1, com uma pequena diferenciação da Região Nordeste, já constatada e referida nos resultados anteriores. No entanto, podemos notar que ocorre uma clara cisão entre os grupos que fracassam e os que obtêm sucesso15. Do lado direito do campo semântico encontram-se os grupos que obtêm sucesso, os quais estão saturados pela positividade das características, seja no plano dos traços de cultura e de natureza, seja no plano das emoções e sentimentos. Nesse campo semântico encontram-se ainda os grupos percebidos como brancos em termos da cor da pele. O campo semântico

15 O Eigenvalue nesse tipo de análise é um indicador da forma mais adequada de interpretação dos dados. De modo que, quanto maior o seu valor numa dimensão, maior o poder interpretativo dos dados nessa dimensão. No caso específico dos resultados encontrados, a forma mais adequada de leitura é a que opõe os dois eixos verticais da dimensão 1, uma vez que o Eigenvalue dessa dimensão é muito maior do que o da dimensão 2. Embora se possa ler, ainda, por quadrantes, para preservar o poder das duas dimensões. 
colocado à esquerda, por sua vez, estrutura-se pelo fracasso (brancos e negros), é saturado pela negatividade e caracteriza-se pelos grupos enegrecidos, ou seja, aqueles que foram percebidos como negros ou como mulatos.

Figura 1: Análise de Correspondências Múltiplas (Homals) dos indicadores de infrahumanização dos grupos (sentimentos e emoções, traços de natureza e de cultura) e da cor atribuída aos grupos (Negros, Mulatos ou Brancos), em função da Região de resposta $(n=175)$

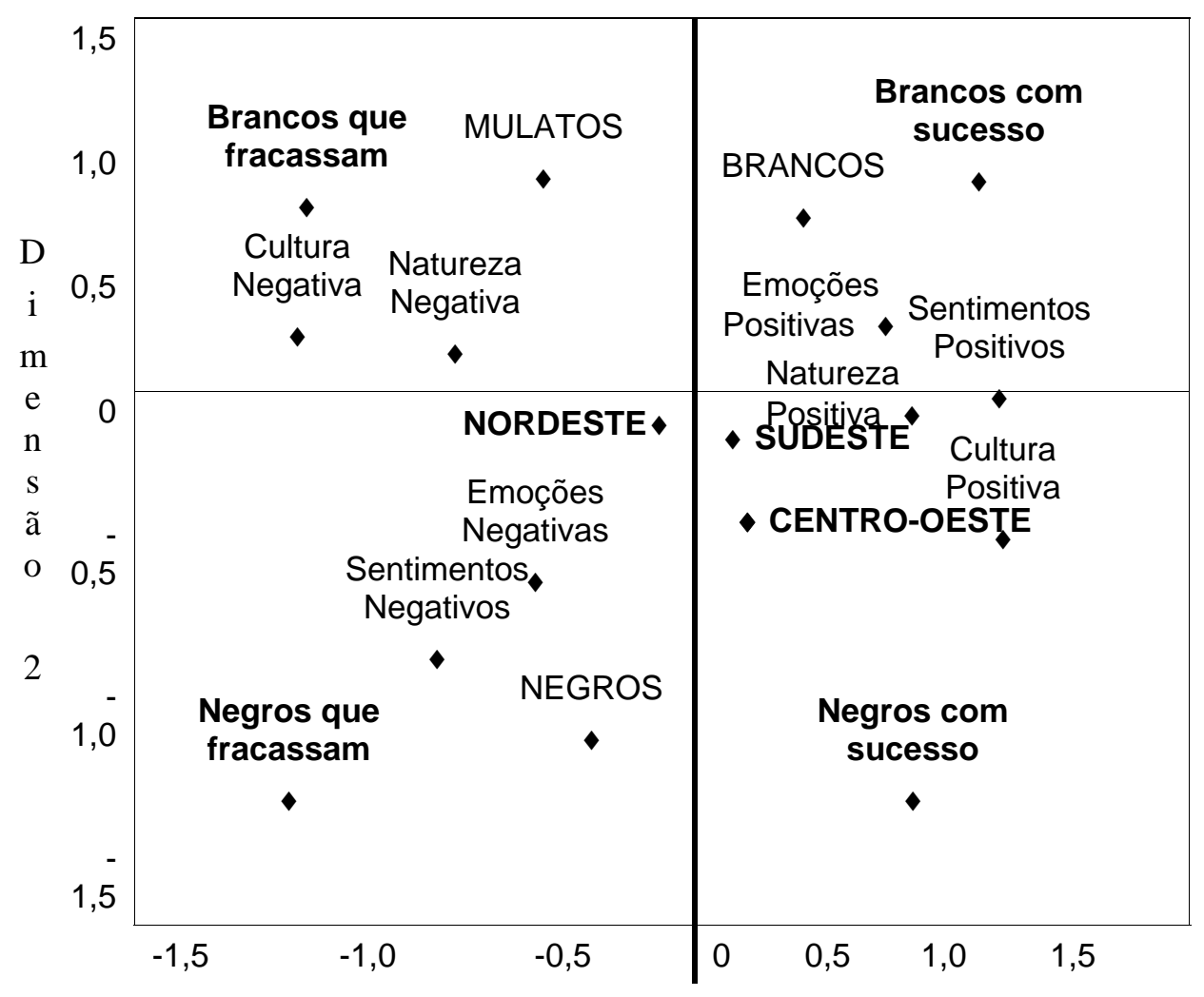

Dimensão 1

Eigenvalues: $\left\{\begin{array}{l}\text { Dimens. } 1=.39 \\ \text { Dimens. } 2=.16\end{array}\right.$ 
Numa leitura mais detalhada, por quadrantes, podemos notar que os brancos que fracassam são percebidos como mulatos, e caracterizados em termos de cultura e natureza negativas. Já os brancos com sucesso, são percebidos como brancos e caracterizados em termos de emoções, sentimentos e traços de natureza positiva. Os negros que fracassam, por sua vez, são percebidos como negros e avaliados em termos de emoções e sentimentos negativos. Enquanto os negros que obtêm sucesso estão semanticamente mais próximos das características de cultura positivas e no vértice de um triângulo imaginário, cuja origem estaria, de um lado, na percepção da cor branca e, do outro, na cor negra.

\section{Considerações Finais}

Este artigo apresentou um estudo em três regiões do Brasil, cujo objetivo principal foi analisar o papel da performance socioeconômica e da cor da pele dos grupos, no modo como eles são branqueados e infra-humanizados. Para a consecução desse objetivo, analisamos a infra-humanização em termos de uma atribuição diferenciada de sentimentos ou emoções secundárias aos grupos e da desculturalização. As nossas principais hipóteses referiam efeitos da cor da pele e da performance na infra-humanização dos grupos e o branqueamento dos grupos com sucesso. Os resultados indicaram que as hipóteses se confirmam parcialmente. Os grupos que fracassam são mais infra-humanizados do que os que obtêm sucesso, seja no plano dos sentimentos, seja no plano da desculturalização, e os grupos com sucesso são percebidos como mais brancos do que os que fracassam.

Os resultados obtidos indicam que não ocorre um efeito direto entre a cor da pele dos grupos na infra-humanização, mesmo quando utilizamos uma estratégia de coleta de dados menos obstrutiva ou mais disfarçada, como foi o caso desse estudo. Esses resultados confirmam os nossos pressupostos teóricos de que cada contexto de relações racializadas possui uma forma específica de racismo, que apresenta manifestações particulares. No Brasil, diferentemente da Europa, onde esses indicadores de infra-humanização foram criados e se mostram efetivos em vários estudos (Correia et al., 
2000; Leyens et al., 2001; Lima \& Vala, 2002; Moscovici \& Pérez, 1999), a infra-humanização dos negros passa, necessariamente, pelo branqueamento, como indicam os resultados desse estudo. Cabe referir, ainda, citando Florestan Fernandes (1966), que a principal característica e mesmo obsessão das relações racializadas no Brasil, ao longo do tempo, é o preconceito de ter preconceito. De tal maneira que os brasileiros, muito antes dos europeus e dos norte-americanos, tendem a ser muito ciosos sobre a sua auto-imagem de pessoa igualitária e não racista, pelo menos ao nível formal. Esse fato pode implicar um aumento da obstrutividade dos indicadores de racismo nos estudos feitos no Brasil em relação aos da Europa.

Importante referir ainda que, embora a Região de resposta produza em alguns casos padrões diferenciados de expressão da infra-humanização ou racismo contra os negros, de uma maneira geral, nas três regiões pesquisadas, os resultados indicam uma forte associação entre cor da pele e infrahumanização. Os grupos percebidos como mais negros são mais infrahumanizados do que os grupos branqueados.

Assim, como argumenta Lima (2003), parece que estamos diante de um racismo camaleônico, que utiliza o notável caleidoscópio de cores que compõem a sociedade brasileira, para construir um tipo de representação social que associa o fracasso à cor negra e o sucesso à cor branca. Essa forma brasileira de racismo pode fazer mudar subjetivamente a cor de um indivíduo, a fim de manter intactas as crenças coletivas e as atitudes negativas associadas à categoria de pertença desse indivíduo. Nesse quadro interpretativo, os Negros não são positivos ou negativos porque são Negros, mas são percebidos positivamente apenas quando são branqueados e, negativamente, quando enegrecidos.

Em futuras investigações, consideramos importante analisar se esse padrão de resultados se verifica em outros contextos e com outras amostras, além dos estudantes universitários. 
Cor da pele, sucesso social e infra-humanização

\title{
Agradecimentos
}

Gostaríamos de agradecer aos colegas Cícero Roberto Pereira, da Universidade Católica de Goiás e José Rodorval Ramalho, da Universidade Federal de Sergipe, que colaboraram na coleta dos dados.

Lima, M. E. O., \& Vala, J. (2005). The colour of success: Effects of the social and economical performance on the whitening and on the infrahumanization of Blacks in Brazil. Psicologia USP, 16 (3), 143-165.

\begin{abstract}
This study analyse the impact of skin colour and social performance on the whitening and infra-humanization of Black people. The main hypotheses are: a) the Blacks will be more infra-humanized than the Whites, b) the groups that are socially unsuccessful will be more infrahumanized than the groups that obtain success, and c) the groups with success will be perceived as whiter than the ones that are unsuccessful. The results of the 175 white students, of three private universities, of three regional capitals of Brazil, indicate that the hypotheses were partially confirmed. At the level of the subjective perception of skin colour, the unsuccessful groups were infra-humanized when compared to those that obtain success, and the groups that obtain success were whitened, and the unsuccessful groups blackened. The infra-humanization of the blacks is mediated by the skin whitening. These results are discussed in the context of the new psychosociological theories about racism.
\end{abstract}

Index terms: Social groups. Racism. Sociocultural factors.

Lima, M. E. O., \& Vala, J. (2005). La couleur du sucess: les effets de la réussite sociale et economique dans le branchissement et l'infrahumanisation des personnes noirs au Brésil. Psicologia USP, 16 (3), 143-165.

Résumé : Cette étude analyse les effets de la couleur de la peau et de la réussite sociale dans le "blanchissement" et l'infra-humanisation. Les hypothèses formulées sont les suivantes : a) les personnes noirs seront plus 
infra-humanisées que les personnes blanches ; b) ceux qui échouent seront aussi plus infra-humanisés que ceux qui réussissent ; c) les groupes qui réussissent seront perçus comme plus blancs que ceux qui échouent. Les données, recueillis auprès de 175 étudiants blancs appartenant à trois Universités privées, dans trois différentes régions du Brésil, montrent que : les groupes qui échouent sont plus infra- humanisés que ceux qui réussissent; ceux que échouent sont aussi perçus comme plus noirs que ceux qui réussissent ; la couleur perçue de la peau est un médiateur de la relation entre "le fait d'être noir » et le fait d’être infra-humanisé. Les résultats sont discutés à la lumière des nouvelles théories de la psychologie sociale sur le racisme.

Mots-clés: Groupes sociaux. Racisme. Context sociocultural.

\section{Referências}

Adorno, S. (1996). Violência e racismo: discriminação no acesso à justiça penal. In L. M. Schwarcz \& R. da S. Queiroz (Orgs.), Raça e diversidade (pp. 255-275). São Paulo: EDUSP.

Alencastro, L. F. de (1998). Vida privada e ordem privada no Império. In L. F. de Alencastro (Coord.), História da vida privada no Brasil. Império: a corte e a modernidade nacional (Vol. 2, pp. 11-94). São Paulo: Companhia das Letras.

Bar-Tal, D. (1989). Group beliefs: A conception for analyzing group structure, processes, and behavior. New York: Springer-Verlag.

Bastide, R., \& Fernandes, F. (1959). Brancos e negros em São Paulo. São Paulo: Companhia Editora Nacional.

Camino, L., Silva, P., Machado, A., \& Pereira, C. (2001). A face oculta do racismo no Brasil: uma análise psicossociológica. Revista de Psicologia Política, 1, 13-36.

Campbell, D. T, \& McCandless, B. R. (1951). Ethnocentrism, xenophobia, and personality. Human Relations, 4, 185-192.

Carneiro, M. L. T. (1998). O racismo na história do Brasil: mito e realidade. São Paulo: Ática

Carvalho, H. (1990). Vitimologia e medo do crime: aplicação de análise factorial de correspondências múltiplas. Tese de Doutoramento, Instituto Superior de Ciências do Trabalho e da Empresa, Lisboa. 
Correia, I., Brito, R., Vala, J., \& Pérez, J. (2001). Normes antiracistes et persistance du racisme flagrant: analyse comparative des attitudes face aux Tziganes et face aux noirs au Portugal (Centro de Investigação e Intervenção Social do ISCTE). (Manuscrito não publicado).

Degler, C. N. (1971). Nem preto nem branco: escravidão e relações raciais no Brasil e no EUA. Rio de Janeiro: Labor.

Fernandes, F. (1965). A integração do negro na sociedade de classes. São Paulo: Dominus.

Fernandes, F. (1966). O Negro no mundo dos brancos. São Paulo: Difusão Européia do Livro.

Fernandes, F. (1989). O significado do protesto negro. São Paulo: Cortez.

França, D. X., \& Monteiro, M. B. (2002). Identidade racial e preferência em crianças brasileiras de 5 a 10 anos. Psicologia, 16(2).

Gaertner, S. L., \& Dovidio, J. F. (1986). The aversive form of racism. In J. F. Dovidio \& S. L. Gaertner (Eds.), Prejudice, discrimination, and racism: Theory and research (pp. 61-89). Orlando, FL: Academic Press.

Guimarães, A. S. A. (1999). Racismo e anti-racismo no Brasil. São Paulo: Editora 34.

Harris, M. (1970). Referential ambiguity in the calculus of the brazilian racail identity. In N. Whitten \& J. Szwed (Eds.), African-American anthropology (pp. 76-86). New York: The Free Press.

Katz, I., \& Hass, R. G. (1988). Racial ambivalence and American value conflict: correlational and priming studies of dual cognitive structures. Journal of Personality and Social Psychology, 55, 893-905.

Kinder, D. R., \& Sears, D. O. (1981). Prejudice and politics: symbolic racism versus racial threats to the good life. Journal of Personality and Social Psychology, 40, 414-431.

Leyens, J. P., Paladino, P., Rodriguez-Torres, R., Vaes, J., Demoulin, S., RodriguezPerez, A., \& Gaunt, R. (2000). The emotional side of prejudice: the attribution of secondary emotions to ingroups and outgroups. Personality and Social Psychology Review, 2, 186-197.

Leyens, J. P., Rodriguez-Perez, A., Rodriguez-Torres, R., Gaunt, R., Paladino, P., Vaes, J., \& Demoulin, S. (2001). Psychological essentialism and the differential attribution of uniquely human emotions to ingroups and outgroups. European Journal of Social Psychology, 31, 395-411. 
Lima, M. E. O. (2003). Normas sociais e racismo: efeitos do igualitarismo e do individualismo meritocrático na infra-humanização dos Negros. Tese de Doutorado, Instituto Superior de Ciências do Trabalho e da Empresa. Lisboa.

Lima, M. E. O., \& Vala, J. (2002). Individualismo meritocrático, diferenciação cultural e racismo. Análise Social, 37, 181-207.

McConahay, J. B., \& Hough Junior, J. C. (1976). Symbolic racism. Journal of Social Issues, 32, 23-45.

Moscovici, S., \& Pérez, J. A. (1997). Prejudice and social representations. Papers on Social Representations, 6, 27-36.

Moscovici, S., \& Pérez, J. A. (1999). A extraordinária resistência das minorias à pressão das maiorias: o caso dos ciganos. In J. Vala (Coord.), Novos racismos: perspectivas comparativas (pp. 103-119). Oeiras, Portugal: Celta.

Pestana, H. M., \& Gageiro, J. N. (1998). Análise de dados para ciências sociais: a complementaridade do SPSS. Lisboa: Sílabo.

Pettigrew, T. F., \& Meertens, R. W. (1995). Subtle and blatant prejudice in western Europe. European Journal of Social Psychology, 25, 57-75.

Piza, E. (2000). Branco no Brasil? Ninguém sabe, ninguém viu. In A. S. A., Guimarães \& L. Huntley (Orgs.), Tirando a máscara: ensaios sobre racismo no Brasil (pp. 97126). São Paulo: Paz e Terra.

Schwarcz, L. M., \&. Queiroz, R. da S. (Orgs.). (1996). Raça e diversidade. São Paulo: EDUSP.

Schwartz, S. H., \& Struch, N. (1989). Values, stereotypes, and intergroup antagonism. In D. Bar-Tal, C. F. Graumann, A. Kriglanski \& W. Stroebe (Eds.), Stereotyping and prejudice: changing conceptions (pp. 151-167). New York: Springer-Verlag.

Skidmore, T. (1989). Realidades raciais e pensamento racial depois da abolição. In T. Skidmore. Preto no branco: raça e nacionalidade no pensamento brasileiro (pp. 55-94). São Paulo: Paz e Terra.

Tajfel, H. (1978). Social categorization, social identity and social comparison. In H. Tajfel (Ed.), Differentiation between social groups: studies in the social psychology of intergoup relations (pp. 61-76). Londres: Academic Press.

Turra, C., \& Venturi, G. (1995). Racismo cordial: a mais completa análise sobre preconceito de cor no Brasil. São Paulo: Ática.

Vala, J., \& Lima, M. E. O. (2002). Diferenciação social, racialização e etnicização de minorias: ambivalências e contradições. In L. Lima, P. Castro \& M. Garrido (Orgs.), Novas orientações da Psicologia Social em Portugal. Lisboa: Livros Horizonte. 
Vala, J., Brito, R., \& Lopes, D. (1999). Expressões dos racismos em Portugal: perspectivas psicossociológicas. Lisboa: Editora do Instituto de Ciências Sociais da Universidade de Lisboa.

Vanneman, R. D., \& Pettigrew, T. F. (1972). Race and relative deprivation in the urban United States. Race, 13, 461-486.

Recebido em: 28.01.2004

Aceito em: 05.03.2004 
